\title{
Motor activity of the human Fallopian tube in vitro in relation to plasma concentration of oestradiol and progesterone, and the influence of noradrenaline
}

\author{
G. Helm*, Ch. Owman $\dagger$, N.-O. Sjöberg* and B. Walles $\dagger$ \\ Departments of * Obstetrics and Gynecology and $\dagger$ Histology, University of Lund, Lund, Sweden
}

\begin{abstract}
Summary. The contractile pattern of the human Fallopian tube was studied in preparations from the ampullary and isthmic regions mounted in an organ bath for measurement of longitudinal and circular smooth muscle activity. The material was obtained during the follicular, ovulatory, and luteal phases of the cycle as defined primarily from plasma oestrogen and progesterone values. The frequency of the spontaneous contractions increased progressively during the follicular phase to become maximal around ovulation. There was no consistent difference between isthmus and ampulla; the circular musculature had a higher frequency than the longitudinal during the ovulatory phase. Noradrenaline $\left(3 \times 10^{-6} \mathrm{M}\right)$ in general potentiated the difference in frequency seen between the ovulatory phase on the one hand and the follicular and luteal phases on the other. Contractile activity, assessed by planimetric integration of the curve on the pen-recorder trace, increased markedly during the ovulatory phase in all types of smooth muscle preparations. Exogenous noradrenaline inhibited spontaneous motor activity in preparations from pregnant or post-menopausal women or from women taking combined-type oral contraceptives. This effect was most marked in the circular muscle. Thus the different regions of the human Fallopian tube in vitro show various patterns of spontaneous motor activity in relation to the plasma steroid concentrations during the menstrual cycle. Responses to exogenous noradrenaline also varied, indicating that the effects of endogenous noradrenaline released from sympathetic nerves may vary similarly.
\end{abstract}

\section{Introduction}

The Fallopian tube is engaged in various transport processes essential for reproduction (see Pauerstein \& Eddy, 1979). Within the ampullary region the egg is not transported in a simple continuous pattern, but makes a complex to-and-fro movement providing a net forward transport velocity of $\sim 10 \mathrm{~mm} / \mathrm{min}$ (Verdugo, Blandau, Tam \& Halbert, 1976). This is probably governed by a combination of smooth muscle activity and the motility of cilia, resulting in an asymmetric frictional effect (Halbert, Tam, Adams \& Blandau, 1976; Eddy, Flores, Archer \& Pauerstein, 1978). In women, egg transport is characterized by a retention in the ampulla, near the ampullary-isthmic junction, for $70-80 \mathrm{~h}$ followed by a rapid transit through isthmus in $<10$ h (Cheviakoff et al., 1976; Croxatto et al., 1978). This tube-locking mechanism, as well as the rapid passage into the uterus, seems to be effected primarily by tubal muscular activity (Anand \& Guha, 1978). In most species investigated, including man, the overall time required for the transport of the ovum from the ovary to the uterus is 3-4 days (Pauerstein \& Eddy, 1979). There is strong evidence that the tubal motor activity is influenced by local adrenergic neural mechanisms (Brundin, 1965; Owman, Rosengren \& Sjöberg, 1967).

The timing of the different components in the complex process of ovum transport is under 
the influence of sex hormones (for references, see Harper et al., 1976). Most of the available information has been obtained from laboratory animals and, although much has been learnt about tubal motility in women from recordings by implanted pressure transducers, little is known about the mechanisms controlling tubal transport functions. The present study on isolated tubal tissues from women was undertaken to gain information about smooth muscle activity, and the total response to the sympathetic neurotransmitter, noradrenaline, during the different phases of the menstrual cycle.

\section{Material}

\section{Materials and Methods}

The human tubal material was obtained by abdominal hysterectomy (because of adenomyosis, myoma, or preinvasive carcinoma of the cervix), salpingo-oophorectomy (for benign ovarian cysts), and salpingectomy (because of sterilization). One or both Fallopian tubes were taken from 86 adult, regularly menstruating patients aged $30-48$ years. Tubal material was also obtained from 7 women (aged 31-47 years) taking contraceptive pills of the combined steroid type (50 $\mu \mathrm{g}$ ethinyloestradiol plus $0.25-3 \mathrm{mg}$ synthetic gestagen), 3 pregnant patients (aged 30-41 years) in the first trimester, and 6 menopausal women (aged 46-58 years). Only oviducts with normal macroscopic appearance were used. Tissues from patients with suspected hormonal disturbances or receiving treatment with $\beta$-receptor antagonists or hormones (except for contraceptive pills as above) were not included.

Morphine chloride $(10 \mathrm{mg})$ and scopolamine bromide $(0.4 \mathrm{mg})$ were given as preanaesthetic medication. Anaesthesia was induced by pentobarbitone sodium administered i.v., followed by inhalation of a mixture of dinitrous oxide and oxygen. Succinylcholine iodide was given initially i.v. as muscle relaxant, followed by pancuronium bromide.

\section{Definition of hormonal state}

The cyclic stage was estimated on the basis of (1) the patient's menstrual cycle as noted in the record, usually together with histological examination of endometrial material obtained by curettage of the uterine cavity during the operation, (2) sectioned and stained endometrial preparations, and (3) plasma steroid levels.

Blood (approximately $10 \mathrm{ml}$ ) for determination of progesterone and oestradiol concentrations in plasma was withdrawn from a vein within $1 \mathrm{~h}$ before opening of the abdomen. The progesterone radioimmunoassay was similar to that described by Youssefnejadian, Florensa, Collins \& Sommerville (1972). The antiserum (FO 22-5-73), which was highly specific for progesterone, was supplied by Dr Kjell Martinsson (Stockholm) and was used at a dilution of $1: 1500$. The antiserum was raised in sheep against BSA conjugated with $11 \alpha$-hydroxyprogesterone. Usually 25-100 $\mu \mathrm{l}$ plasma were extracted twice with petroleum ether. The unbound steroid was removed by addition of dextran-coated charcoal. The sensitivity of the assay was $25 \mathrm{pg} / \mathrm{ml}$ and the inter- and intra-assay coefficients of variation were 18.7 and $10.5 \%$. Cross-reaction of the antiserum was $<10 \%$ to $17 \alpha$-hydroxyprogesterone and $<0.05 \%$ to $20 \alpha$-dihydroprogesterone. The radioimmunoassay for oestradiol was that described by Lindberg, Lindberg, Martinsson \& Johansson (1974). The antiserum was raised in sheep against oestradiol-17- $\beta$-oxime conjugated with BSA and used at a dilution of $1: 100000$. Extractions of $1 \mathrm{ml}$ plasma were with diethyl ether. The unbound steroid was removed by addition of dextran-coated charcoal. The assay sensitivity was $5 \mathrm{pg}$ oestradiol $/ \mathrm{ml}$ and the inter- and intra-assay coefficients of variation were 16.2 and $9.9 \%$. Cross-reaction of the antiserum to oestradiol-17 $\alpha$ was $0.7 \%$, and it was $11 \%$ for oestrone (Batra, Bengtsson \& Sjöberg, 1979; Batra, Owman, Sjöberg \& Thorbert, 1979).

The plasma hormone concentrations were used to confirm the separation of the material into three main stages, based on the patient's menstrual record and the histological examinations: 


\section{Progesterone}

Follicular phase

Ovulatory phase

Luteal phase $\leqslant 2 \mathrm{ng} / \mathrm{ml}$

$\leqslant 2 \mathrm{ng} / \mathrm{ml}$

$>2 \mathrm{ng} / \mathrm{ml}$
Oestradiol

$$
\leqslant 100 \mathrm{pg} / \mathrm{ml}
$$

$>100 \mathrm{pg} / \mathrm{ml}$

Range of values

\section{Tubal preparations}

Immediately after removal, the oviducts were placed in ice-cold Krebs-Ringer buffer solution (see below) for $<1 \mathrm{~h}$ or for as long as $20 \mathrm{~h}$ (at $4^{\circ} \mathrm{C}$ ). Pilot studies on tissues before and after storage from the same patients have shown no change in motor functions. Before mounting in the organ bath, a thin $(2 \mathrm{~mm}$ o.d.) probe was introduced into the lumen from the ampullary end to localize the ampullary-isthmic junction, where the oviduct was divided. A few $\mathrm{mm}$ of the adjacent isthmic and ampullary portions were discarded. The next $10 \mathrm{~mm}$ of the two regions were used for recordings of isometric smooth muscle activity. A 4-mm long cylinder was cut and mounted for registration of mainly circular activity, and the remaining 6-mm piece was used for recordings of mainly longitudinal smooth muscle activity. The identity of the ampullary and isthmic preparations was confirmed by microscopy of haematoxylin and eosin-stained sections. To estimate the thickness of the various layers of the tubal wall, avoiding as far as possible shrinkage artefacts, adjacent pieces of ampulla and isthmus were frozen to $-80^{\circ} \mathrm{C}$, sectioned in a cryostat at $20 \mu \mathrm{m}$ thickness, stained with haematoxylin and eosin, and measured in a microscope.

The pieces prepared for circular activity measurements were mounted between two L-shaped metal holders in organ baths. The pieces for longitudinal recordings were tied to two metal hooks by silk ligatures. All four preparations were connected to Grass FTO3C force-displacement transducers, and their signals were amplified and recorded by a Grass Model 7B Polygraph. The organ baths contained a modified Krebs-Ringer solution of the following composition (mmol): $\mathrm{NaCl} 118, \mathrm{KCl} 4 \cdot 5, \mathrm{CaCl}_{2} .2 \mathrm{H}_{2} \mathrm{O} 2 \cdot 5, \mathrm{MgSO}_{4} .7 \mathrm{H}_{2} \mathrm{O} 1 \cdot 0, \mathrm{NaHCO}_{3} 25, \mathrm{KH}_{2} \mathrm{PO}_{4} 1 \cdot 0$, glucose 6.0. The temperature of the baths was thermostatically maintained at $37^{\circ} \mathrm{C}$ and the buffer solution was continuously aerated with a mixture of $95 \% \mathrm{O}_{2}$ and $5 \% \mathrm{CO}_{2}$ giving a pH of 7.4 (range 7.25-7.55). All preparations were given an initial passive tension of $500 \mathrm{mg}$ force and were allowed to accommodate for 45-60 min. During this period the tension decreased and the preparations started to contract spontaneously.

\section{Analysis of data}

Noradrenaline (L-artenerol hydrochloride, Sigma; dissolved in $0.9 \% \mathrm{w} / \mathrm{v} \mathrm{NaCl}$ with the addition of $0.2 \mathrm{mg}$ ascorbic acid $/ \mathrm{ml}$ as antioxidant) was usually given as one standard dose ( $3 \times 10^{-6} \mathrm{M}$ final concentrations in the organ bath), but the action of increasing doses was also tested during cumulative application. The frequency of the spontaneous contractions was measured during one 3-min period immediately before administration of the amine and compared to the frequency of contractions during an equal period just after the administration. Frequency determinations in the more regularly contracting circular preparations did not present any difficulties. The longitudinally orientated preparations sometimes contracted irregularly with individual deflections of variable size. All clearly distinct deflections were included in the frequency estimations. The degree of increase or reduction in activity was obtained by using a planimeter to integrate the curves over the 3-min periods. The base line was defined as the lowest level of tone from which the individual deflections orginated during the total 6-min measurement period. The noradrenaline-induced change in activity of the preparations was often associated with alterations in the amplitude of the individual rhythmic contractions, but was too inconsistent to be useful.

Mean values (and standard errors) of the various characteristics of motor activity in the 
different types of smooth muscle preparations were related to the phase of the menstrual cycle and differences were compared by Student's $t$ test. Attempts were also made to obtain a simultaneous correlation of individual values for plasma steroid hormones and the type of contraction in a three-dimensional system covering the steroid levels of the entire menstrual cycle. The original values for the recorded change in smooth muscle activity were plotted in a two-dimensional square grid in which the plasma levels of oestradiol and progesterone were represented in the $x$ and $y$ axes. Each square is assigned a value equal to the average of the observation inside the square. Because the observation points were placed very irregularly in the examined area, some squares did not include any observation. The values for these squares were approximated from the closest observations of adjacent squares using three different interpolation methods: double-linear interpolation, quadratic interpolation, and distanceweighing interpolation (Bladh \& Jern, 1980). The relationship between the regular values obtained for the motor response and the plasma steroid levels were then depicted with the use of a three-dimensional colour ink jet plotter (Smeds, 1973) available at the Computer Center of the University of Lund where the diagrams were devised in collaboration with $M$. Jern and L. Persson.

\section{Results}

As shown in Text-fig. 1, there was no consistent difference in contraction frequency between the isthmic and ampullary preparations, and the circular and longitudinal muscles differed only in the isthmus $(P<0.01)$ and at the time of ovulation.

An over-all picture of the cyclic variations in the frequency of the spontaneous contraction was obtained with the three-dimensional computer plots. Text-figure 2 shows that for the circular muscle there was a steady increase in frequency during the follicular phase (increasing oestradiol and low progesterone) towards a maximum, which was reached around the time of ovulation (i.e. highest oestradiol values, but low progesterone), followed by a return to a lower frequency in the course of the luteal phase (increasing progesterone levels). This pattern of changes was similar in the circular musculature of the isthmus and the ampulla. There were no such consistent cyclic changes in frequency of the longitudinally orientated tubal preparations.

The menopausal patients as well as those taking steroid-type contraceptives showed little

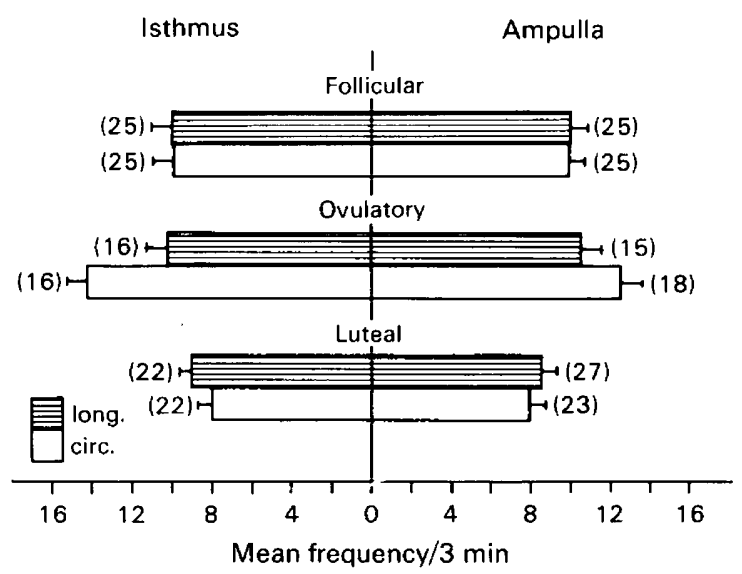

Text-fig. 1. Frequency of spontaneous tubal contractions (isthmus and ampullary longitudinal and circular musculature) during the follicular, ovulatory and luteal phases of the menstrual cycle. Values are means + s.e.m. for the no. of preparations in parentheses. 


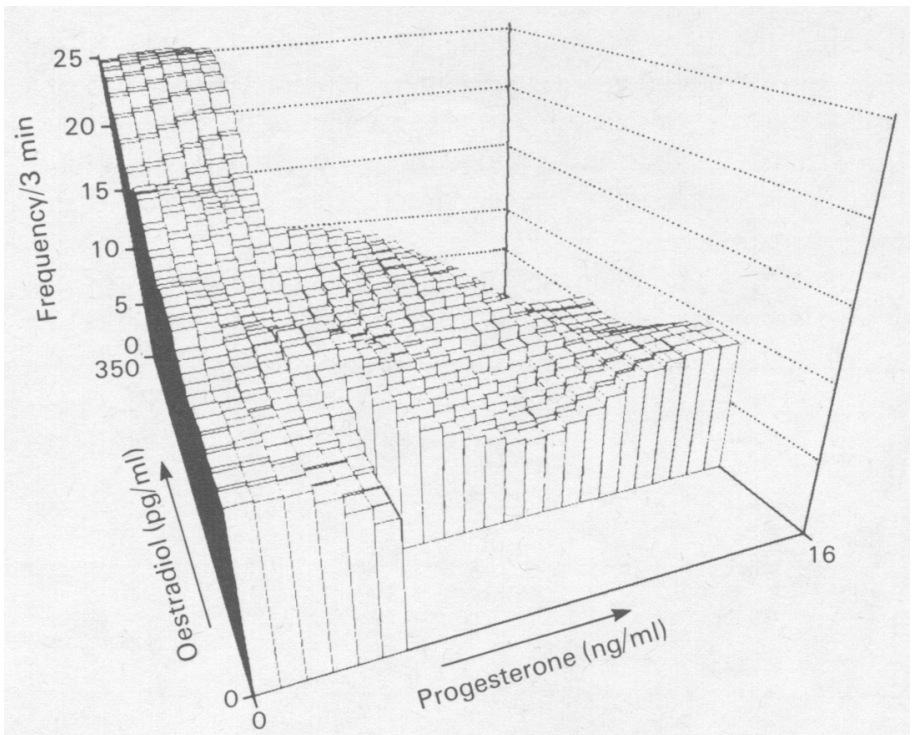

Text-fig. 2. Three-dimensional computer plot, based on the entire material from the circularly orientated smooth musculature of the isthmus $(n=63)$, illustrating the frequency of spontaneous contractions in relation to the plasma levels of oestradiol and progesterone. The original, irregular frequency values have been transformed into regularity by computerized interpolation (see text).

individual variation in plasma steroid levels; progesterone concentration was low, and the mean oestradiol value corresponded to that expected during the early and late follicular phase, respectively (Table 1). There was no statistically significant difference in the frequency of the spontaneous contractions of the various types of preparations in these two groups compared with preparations taken in the follicular phase of normally menstruating women (Text-fig. 1). The contraction frequency in early pregnancy was lower than that during the luteal phase of the cycle but was significantly different only for the ampullary preparations $(P<0.05)$.

Table 1. Absolute frequency of spontaneous contractions, and \% change in area under the curves of motor activity induced by $3 \times 10^{-6} \mathrm{M}$-noradrenaline, in comparison with the condition before treatment, in four types of human oviduct smooth muscle preparations (increased activity corresponds to positive values, reduced activity to negative values)

\begin{tabular}{|c|c|c|c|c|c|}
\hline \multirow{2}{*}{$\begin{array}{l}\text { Plasma steroids before } \\
\text { operation } \\
\left(\mathrm{E}_{2}: \mathrm{pg} / \mathrm{ml} ; \mathrm{P}: \mathrm{ng} / \mathrm{ml}\right)\end{array}$} & \multirow[b]{2}{*}{ Measurement } & \multicolumn{2}{|c|}{ Isthmus } & \multicolumn{2}{|c|}{ Ampulla } \\
\hline & & Circular & Longitudinal & Circular & Longitudinal \\
\hline $\begin{array}{c}\text { Menopause }(n=6) \\
E_{2}=38 \cdot 7 \pm 6 \cdot 3 \\
P=0.4 \pm 0.2\end{array}$ & $\begin{array}{l}\text { Frequency } \dagger \\
\% \text { change in area }\end{array}$ & $\begin{array}{c}10 \cdot 7 \pm 1 \cdot 2 \\
-12 \cdot 3 \pm 3 \cdot 1^{* *}\end{array}$ & $\begin{array}{r}8.3 \pm 0.1 \\
-6 \cdot 7 \pm 9 \cdot 8\end{array}$ & $\begin{array}{c}12 \cdot 0 \pm 1.6 \\
-10.5 \pm 4 \cdot 3^{*}\end{array}$ & $\begin{array}{r}10 \cdot 2 \pm 1.4 \\
-2 \cdot 7 \pm 6 \cdot 2\end{array}$ \\
\hline $\begin{array}{l}\text { Steroid contraceptives }(n \\
\mathbf{E}_{2}=70 \cdot 7 \pm 17 \cdot 5 \\
\mathbf{P}=0.4 \pm 0 \cdot 1\end{array}$ & $\begin{array}{l}=7) \\
\text { Frequency } \dagger \\
\% \text { change in area }\end{array}$ & $\begin{array}{c}11.4 \pm 2.2 \\
-21.7 \pm 7.0^{* *}\end{array}$ & $\begin{array}{c}9 \cdot 2 \pm 1 \cdot 2 \\
12 \cdot 0 \pm 11 \cdot 0\end{array}$ & $\begin{array}{c}9.3 \pm 1.9 \\
-19.0 \pm 5 \cdot 1^{* * *}\end{array}$ & $\begin{array}{c}11.7 \pm 1.7 \\
-0.7 \pm 10.3\end{array}$ \\
\hline $\begin{array}{l}\text { Pregnancy }(n=3) \\
E_{2}=746 \cdot 7 \pm 382 \cdot 9 \\
P=21 \cdot 2 \pm 8 \cdot 7\end{array}$ & $\begin{array}{l}\text { Frequency }{ }^{\dagger} \\
\% \text { change in area }\end{array}$ & $\begin{array}{c}6.7 \pm 1.2 \\
-29 \cdot 3 \pm 10.4\end{array}$ & $\begin{aligned} 6 \cdot 3 & \pm 2 \cdot 4 \\
-35 \cdot 0 & \pm 9 \cdot 3^{*}\end{aligned}$ & $\begin{array}{c}5 \cdot 3 \pm 0.3 \\
-20 \cdot 7 \pm 10 \cdot 9\end{array}$ & $\begin{array}{r}6.0 \pm 1 \cdot 0 \\
-36.0 \pm 8 \cdot 6^{*}\end{array}$ \\
\hline
\end{tabular}

Values are mean \pm s.e.m. for the no. of preparations in parentheses.

Paired $t$ test comparing the motor activity before and after noradrenaline administration: $P<0.05,{ }^{* *} P<0.01$, *** $P<0.001$.

$\dagger$ The absolute frequencies of spontaneous tubal contraction in normally menstruating women during various cyclic stages are illustrated in Text-fig. 1. 
Noradrenaline lowered the contraction frequency of both the isthmic and the ampullar circular preparations in the follicular and luteal phases, but increased that of the longitudinal ampullar preparation in the ovulation period. The mean effect of noradrenaline on the amplitude of the response (i.e. the size of the deflections above the tonic activity) was usually a reduction in all phases and in all types of tissues, although the effects were very variable and no statistically significant difference was apparent.

The noradrenaline-induced changes in surface area under the curves of motor activity are given in Table 2 and the planimetric results for isthmic circular muscle in Text-fig. 3. Contractile

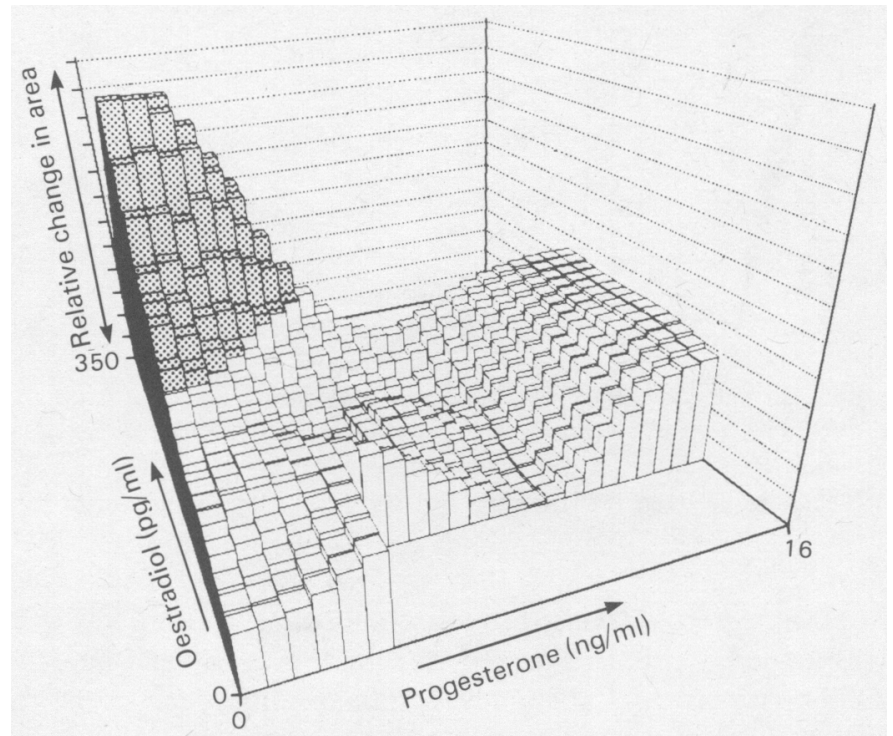

Text-fig. 3. Three-dimensional computer plot, based on the entire material from the circular isthmic smooth musculature $(n=63)$, showing increase (shaded columns) or decrease (open columns) in area under curves of motor activity induced by $3 \times 10^{-6} \mathrm{M}$-noradrenaline, in relation to the plasma levels of oestradiol and progesterone. The relative changes in area were determined planimetrically during equal time periods before and after administration of the amine. The original, irregular values for the area changes thus obtained were transformed into regularity by computerized interpolation (see text).

Table 2. Percentage changes of motor activity induced by $3 \times 10^{-6} \mathrm{M}$-noradrenaline in four types of human oviduct smooth muscle at different phases of the menstrual cycle (increased frequency or area indicated by positive values, reduced frequency or area by negative values)

\begin{tabular}{|c|c|c|c|c|}
\hline \multirow[b]{2}{*}{ Stage of cycle } & \multicolumn{2}{|c|}{ Isthmus } & \multicolumn{2}{|c|}{ Ampulla } \\
\hline & Circular & Longitudinal & Circular & Longitudinal \\
\hline & \multicolumn{4}{|c|}{ Frequency of phasic contractions } \\
\hline \multirow[t]{2}{*}{$\begin{array}{l}\text { Follicular } \\
\text { Ovulatory } \\
\text { Luteal }\end{array}$} & $\begin{array}{c}-11 \cdot 5 \pm 6 \cdot 1(23)^{*} \\
2.6 \pm 4 \cdot 6(19) \\
-8 \cdot 6 \pm 10.2(23)\end{array}$ & $\begin{array}{l}-5 \cdot 5 \pm 4 \cdot 1(26)^{*} \\
-0.6 \pm 7.0(16) \\
-9 \cdot 1 \pm 6 \cdot 2(22)\end{array}$ & $\begin{array}{c}-15.9 \pm 6.5(25)^{* *} \\
2.9 \pm 7.9(18) \\
-7.0 \pm 8.5(23)\end{array}$ & $\begin{array}{c}4 \cdot 6 \pm 4 \cdot 3(25) \\
15 \cdot 5 \pm 5 \cdot 5(15)^{* * *} \\
-6 \cdot 2 \pm 6 \cdot 9(27)\end{array}$ \\
\hline & \multicolumn{4}{|c|}{ Area under the recorded curve } \\
\hline $\begin{array}{l}\text { Follicular } \\
\text { Ovulatory } \\
\text { Luteal }\end{array}$ & $\begin{aligned}-18.8 & \pm 5.4(24)^{* * *} \\
51.2 & \pm 27.2(18) \\
-33.9 & \pm 4.4(23)^{* *}\end{aligned}$ & $\begin{aligned} 37.7 & \pm 24.9(27)^{*} \\
198.1 & \pm 90.1(15) \\
3.7 & \pm 13.0(24)\end{aligned}$ & $\begin{array}{r}-11.8 \pm 7.2(24) \\
17.6 \pm 5.5(18)^{*} \\
-18.4 \pm 6.9(23)^{*}\end{array}$ & $\begin{array}{c}11.2 \pm 7.8(25) \\
51.8 \pm 19.7(15)^{*} \\
-15.5 \pm 8 \cdot 5(27)\end{array}$ \\
\hline
\end{tabular}

Values are mean \pm s.e.m. for the no. of preparations given in parentheses.

Values significantly different from those before noradrenaline treatment (paired $t$ test): ${ }^{*} P<0.05$; ${ }^{* *} P<0.01$; *** $P<0.001$. 
activity was markedly increased around ovulation in all types of muscle preparation, and in the longitudinal isthmus in the follicular phase. Significant reductions occurred during the luteal phase in the circular muscle of isthmic and ampullar preparations and in the follicular phase for the circular isthmus preparation.

In the menopausal, contraceptive-taking and pregnant women (Table 1) noradrenaline always reduced the contractile activity (i.e. the surface area under the curve) in the circularly orientated musculature. The individual responses in the longitudinal musculature varied between slight reduction and enhancement in activity, except during pregnancy when there was a more consistent pattern of reduction.

\section{Discussion}

Most of our knowledge about tubal motor activity and its relationship to ovum transport is based on animal studies, particularly using rabbits (Harper et al., 1976). Despite intensive research, surprisingly little is understood about the significance of tubal motor functions in the pick-up, retention, and transit mechanisms for the ovum (Pauerstein \& Eddy, 1979). Much information about tubal motor activity in women has been gained from pressure recordings in vivo, but these have a number of practical and ethical limitations and are complicated to standardize and evaluate appropriately for quantitative pharmacological analysis (see Maia \& Coutinho, 1976; Guiloff-Fische, Ibarra-Polo \& Gómez-Rogers, 1976). Basic properties of the contractile functions of the human Fallopian tube have therefore been studied under precise conditions in vitro in combination with information of the patient's endocrine state (see also Moawad, Hedqvist \& Kim, 1976; Owman et al., 1976; Paton, 1976).

Lindblom, Hamberger \& Wiqvist (1978) used carefully microdissected and prepared smooth muscle elements from the circular and longitudinal musculature so that the separate types of smooth muscle were accurately defined in terms of their histological orientation, and contamination with blood vessels was to a large extent avoided. A disadvantage is that the complex architecture of the smooth musculature and its relationship to stromal elements in the tube, different for different segments of the organ, is disrupted. In the preparation type used in the present study, the wall of the tube is kept intact except for its connective tissue covering, but the activity is measured principally in the circularly or longitudinally orientated muscle layer. The quantitative contribution of vascular smooth musculature is probably small. The size of the preparations used $(0.7 \mathrm{~mm}$ muscle thickness) is unlikely to constitute a factor influencing oxygenation or diffusion (G. Helm, Ch. Owman, N.-O. Sjöberg \& B. Walles, unpublished observations).

The various patterns of contractile activity were related to different phases of the menstrual cycle on the basis of plasma oestradiol and progesterone determinations (Mishell et al., 1971). The 'ovulatory phase' samples may be a heterogeneous group, consisting not only of material from women in the actual process of ovulation, but also of material from the late follicular and probably also very early luteal stages. Better separation was not possible without access to LH peak data, and the patient's own menstrual cycle anamnesis was not considered sufficiently reliable for further subgrouping of the material.

In general, the frequency, the pattern of cyclic variations in frequency, and the difference between the circular and longitudinal smooth musculature in the composite type of preparations that we used were very similar to those recorded for microdissected smooth muscle preparations from the human tube by Lindblom, Hamberger \& Ljung (1980). The results for women taking combined steroid-type oral contraceptives and for menopausal and pregnant women agree with what could be expected on the basis of the relation found between plasma steroid levels and contraction frequency in patients with normal menstrual cycles (i.e. receiving no contraceptive pills). 
The effect of noradrenaline on tubal motor activity was studied to illustrate the net response that might be expected following sympathetic neurotransmitter release in the tube at different cyclic stages. A standard dose of noradrenaline $\left(3 \times 10^{-6} \mathrm{M}\right)$ was chosen which, in a separate study (G. Helm, Ch. Owman, N.-O. Sjöberg \& B. Walles, unpublished observations), produced an $\alpha$-receptor-mediated effect between the half maximum and maximum response. This concentration at the receptor is in the same order of magnitude as the estimated instantaneous concentration of noradrenaline occurring in the synaptic cleft of a neuromuscular contact during the passage of a sympathetic nerve impulse (Bennett, 1972). Noradrenaline administration into the organ bath potentiated the difference in frequency of contractions during the ovulatory phase in comparison with the follicular and luteal phases. However, the contraction frequency represents only an isolated aspect of tubal motor activity. Planimetric measurement of the surface area under the recorded curve before and after the noradrenaline administration confirmed that an $\alpha$-receptor-mediated sympathomimetic increase in motor activity prevails during ovulation, whereas the contribution by a $\beta$-receptor mediated reduction in motor activity is more prominent during the follicular and ovulatory phases (Moawad et al., 1976; Helm et al., 1981).

There is ample evidence from studies on various laboratory animals that tubal motor activity is influenced by sex steroids, oestradiol being associated with increased tubal contractility, whereas progesterone primarily seems to have an inhibitory effect (Spilman \& Harper, 1974; Borda, Sterin-Borda, Gimeno, Sterin-Speziale \& Gimeno, 1975; Gimeno, Borda, Sterin-Borda, Sterin-Speziale \& Gimeno, 1976). The biological activity of these steroids is probably governed by their concentrations in the tissue rather than in blood. Although there is a similarity in the general pattern of the cyclic fluctuations in the mean steroid concentrations between tubal tissue and plasma, the correlation between these values in each individual patient is poor (Batra, Helm, Owman, Sjöberg \& Walles, 1980). The consistently high tubal motor activity, spontaneous and after sympathomimetic stimulation, found in the present in-vitro study corresponds with high progesterone receptor concentrations in the tissue (Batra et al., 1980). Following ovulation, when the plasma progesterone levels rise, there is a drop in the specific tissue binding of progesterone which is associated with a reduced motor activity in the oviduct after noradrenaline administration. The effect of noradrenaline is less consistent, particularly in the longitudinal smooth musculature, during the follicular phase. This may reflect a progressive increment in $\alpha$-adrenoceptor activity in relation to the $\beta$-receptors during the follicular phase (Moawad et al., 1976), when there are high concentrations of oestradiol and progesterone receptors (Robertson, Landgren \& Guerrero, 1975; Batra et al., 1980; Verhage, Akbar \& Jaffe, 1980).

The human Fallopian tube receives a well-developed adrenergic nerve supply (Brundin \& Wirsén, 1964; Owman et al., 1967). The innervation is particularly dense in the isthmic region. Cyclic variations have been demonstrated in the amounts of sympathetic neurotransmitter in the organ (Owman et al., 1976; Sjöberg, Johansson, Owman, Rosengren \& Walles, 1977) and there is reason to believe that this reflects a steroid-induced effect on processes such as the functional turnover of noradrenaline in the tubal nerves (Takeda \& Doteuchi, 1976). The interaction between sex steroids and sympathetic nerve function is characteristic for the reproductive tract (Alm, Björklund, Owman \& Thorbert, 1979; Thorbert, Alm, Owman \& Sjöberg, 1979), where it seems to be an important component in the function of the entire neuroeffector system (for review, see Thorbert, 1978). We therefore believe that the presence of oestradiol and progesterone can control motor activity of the tubal smooth musculature per se, can influence the way this smooth musculature, via the adrenoceptors, responds to the sympathetic neurotransmitter, and also can affect the function of the tubal adrenergic nerves themselves.

This work was supported by the Swedish Medical Research Council (grant No. 14X-5680) and from Maggie Stephens' foundation. We are deeply grateful to Mrs Barbro Gustavsson for skilful technical assistance. 


\section{References}

Alm, P., Björklund, A., Owman, Ch. \& Thorbert, G. (1979) Tyrosine hydroxylase and dopa decarboxylase activities in the guinea pig uterus: further evidence for a functional adrenergic denervation in association with pregnancy. Neuroscience 4, 145-154.

Anand, S. \& Guha, S.K. (1978) Mechanics of transport of the ovum in the oviduct. Med. Biol. Eng. Comput. 16, 256-261.

Batra, S., Bengtsson, L.Ph. \& Sjöberg, N.-O. (1979) Interrelations between plasma and tissue concentrations of $17 \beta$-estradiol and progesterone during human pregnancy. Clin. Endocr. 11, 603-610.

Batra, S., Owman, Ch., Sjöberg, N.-O. \& Thorbert, G. (1979) Relationship between plasma and uterine oestradiol in pseudopregnant rabbits. J. Reprod. Fert. $56,1-5$.

Batra, S., Helm, G., Owman, Ch., Sjöberg, N.-O. \& Walles, B. (1980) Female sex steroid concentrations in the ampullary and isthmic regions of the human Fallopian tube and their relationship to the plasma concentrations during the menstrual cycle. Am. J. Obstet. Gynec. 136, 986-991.

Bennett, M.R. (1972) Autonomic Neuromuscular Transmission. Cambridge University Press.

Bladh, K. \& Jern, M. (1980) A color plotter system and its applications in geoscience. IEEE Trans. Geosci. Remote Sens. GE. 18, 256-263.

Borda, E., Sterin-Borda, L., Gimeno, M.F., SterinSpeziale, N. \& Gimeno, A.L. (1975) Motility of the rat oviductal tract isolated in different stages of the sex cycle. Int. J. Fert. 20, 170-176.

Brundin, J. (1965) Distribution and function of adrenergic nerves in the rabbit Fallopian tube. Acta physiol. scand. 66, Suppl. 259, 1-57.

Brundin, J. \& Wirsén, C. (1964) Adrenergic nerve terminals in the human Fallopian tube examined by fluorescence microscopy. Acta physiol. scand. 61, 505-506.

Cheviakoff, S., Diaz, S., Carril, M., Patritti, N., Croxatto, H.D., Lljados, C., Ortiz, M.E. \& Croxatto, H.B. (1976) Ovum transport in women. In Ovum Transport and Fertility Regulation, pp. 416-424. Eds M. J. K. Harper, C. J. Pauerstein, C. E. Adams, E. M. Coutinho, H. B. Croxatto \& D. M. Paton. Scriptor, Copenhagen.

Croxatto, H.B., Ortiz, M.E., Diaz, S., Hess, R., Balmaceda, J. \& Croxatto, H.D. (1978) Studies on the duration of egg transport by the human oviduct. II. Ovum location at various intervals following luteinizing hormone peak. Am. J. Obstet. Gynec. 132, $629-634$.

Eddy, C.A., Flores, J.J., Archer, D.R. \& Pauerstein, C.J. (1978) The role of cilia in fertility; an evaluation by selective microsurgical modification of the rabbit oviduct. Am. J. Obstet. Gynec. 132, 814-821.

Gimeno, M.F., Borda, E.S., Sterin-Borda, L., SterinSpeziale, N. \& Gimeno, A.L. (1976) Contractile activity of the oviduct and the mesosalpinx isolated from guinea pigs in different phases of the sex cycle. Effects of several pharmacological influences. Int. $J$. Fert. 21, 31-41.
Guiloff-Fische, E., Ibarra-Polo, A. \& Gómez-Rogers, C. (1976) In vivo human oviductal motility; effects of estrogen and progesterone. In Ovum Transport and Fertility Regulation, pp. 485-494. Eds M. J. K. Harper, C. J. Pauerstein, C. E. Adams, E. M. Coutinho, H. B. Croxatto \& D. M. Paton. Scriptor, Copenhagen.

Halbert, S.A., Tam, P.Y., Adams, R.J. \& Blandau, R.J. (1976) An analysis of the mechanisms of egg transport in the ampulla of the rabbit oviduct. Gynec. Invest. 7, 306-320.

Harper, M.J.K., Pauerstein, C.J., Adams, C.E., Coutinho, E.M., Croxatto, H.B. \& Paton, D.M. (Eds) (1976) Ovum Transport and Fertility Regulation. Scriptor, Copenhagen.

Helm, G., Owman, Ch., Sjöberg, N.-O. \& Walles, B. (1981) Quantitative pharmacological characterization of beta-receptors and two types of alphareceptors mediating sympathomimetic smooth muscle response in the human Fallopian tube at various cyclic stages. Acta physiol. scand. (in press).

Lindberg, B.S., Lindberg, P., Martinsson, K. \& Johansson, E.D.B. (1974) Radioimmunological methods for the estimation of oestrone, oestradiol$17 \beta$ and oestriol in pregnancy plasma. Acta obstet. gynec. scand., Suppl. 32, 5-19.

Lindblom, B., Hamberger, L. \& Wiqvist, N. (1978) Differentiated contractile effects of prostaglandins $\mathrm{E}$ and $F$ on the isolated circular and longitudinal smooth muscle of the human oviduct. Fert. Steril. 30, 553-559.

Lindblom, B., Hamberger, L. \& Ljung, B. (1980) Contractile patterns of isolated oviductal smooth muscle under different hormonal conditions. Fert. Steril. 33, 283-287.

Maia, H. \& Coutinho, E.M. (1976) Motility of the human oviduct in vivo. In Ovum Transport and Fertility Regulation, pp. 221-227. Eds M. J. K. Harper, C. J. Pauerstein, C. E. Adams, E. M. Coutinho, H. B. Croxatto \& D. M. Paton. Scriptor, Copenhagen.

Mishell, D.R., Jr, Nakamura, R.M., Crosignani, P.G., Stone, S., Kharma, R., Nagata, Y. \& Thorneycroft, I.H. (1971) Serum gonadotropin and steroid patterns during the normal menstrual cycle. Am. J. Obstet. Gynec. 111, 60-65.

Moawad, A.H., Hedquist, P. \& Kim, M. (1976) Correlation of plasma estrogens and progesterone levels with the in vitro adrenergic responses in the isthmus of the human oviduct. In Ovum Transport and Fertility Regulation, pp. 276-292. Eds M. J. K. Harper, C. J. Pauerstein, C. E. Adams, E. M. Coutinho, H. B. Croxatto \& D. M. Paton. Scriptor, Copenhagen.

Owman, Ch., Rosengren, E. \& Sjöberg, N.-O. (1967) Adrenergic innervation of the human female reproductive organs. A histochemical and chemical investigation. Obstet. Gynec. 30, 763-773.

Owman, Ch., Falck, B., Johansson, E.D.B., Rosengren, E., Sjöberg, N.O., Sporrong, B., Svensson, K.-G. \& Walles, B. (1976) Autonomic nerves and related amine receptors mediating motor activity in the 
oviduct of monkey and man. A histochemical, chemical and pharmacological study. In Ovum Transport and Fertility Regulation, pp. 256-275. Eds M. J. K. Harper, C. J. Pauerstein, C. E. Adams, E. M. Coutinho, H. B. Croxatto \& D. M. Paton. Scriptor, Copenhagen.

Paton, D. (1976) Adrenergic mechanisms in rabbit and human oviducts. In Ovum Transport and Fertility Regulation, pp. 293-306. Eds M. J. K. Harper, C. J. Pauerstein, C. E. Adams, E. M. Coutinho, H. B. Croxatto \& D. M. Paton. Scriptor, Copenhagen.

Pauerstein, C.J. \& Eddy, C.A. (1979) The role of the oviduct in reproduction; our knowledge and our ignorance. J. Reprod. Fert. 55, 223-229.

Robertson, D.M., Landgren, B.-M. \& Guerrero, R. (1975) Oestradiol receptor levels in the human Fallopian tube during the menstrual cycle. Acta endocr., Copenh. 80, 705-718.

Sjöberg, N.-O., Johansson, E.D.B., Owman, Ch., Rosengren, E. \& Walles, B. (1977) Cyclic fluctuation in noradrenaline transmitter of the monkey oviduct. Acta obstet. gynec. scand. 56, 139-143.

Smeds, B. (1973) A 3-colour ink jet plotter for computer graphics. Bit 13, 181-195.

Spilman, C.H. \& Harper, M.J.K. (1974) Comparison of the effects of adrenergic drugs and prostaglandins on rabbit oviduct motility. Biol. Reprod. 10, 549-554.

Takeda, H. \& Doteuchi, M. (1976) Adrenergic mechan- isms and hormonal status of the oviduct. In Ovum Transport and Fertility Regulation, pp. 307-319. Eds M. J. K. Harper, C. J. Pauerstein, C. E. Adams, E. M. Coutinho, H. B. Croxatto \& D. M. Paton. Scriptor, Copenhagen.

Thorbert, G. (1978) Regional changes in structure and function of adrenergic nerves in guinea-pig uterus during pregnancy. Acta obstet. gynec. scand., Suppl. 79, 1-32.

Thorbert, G., Alm, P., Owman, Ch. \& Sjöberg, N.-O. (1979) Pregnancy-induced alterations in the turnover rate of ${ }^{3} \mathrm{H}$-noradrenaline formed ${ }^{3} \mathrm{H}$-tyrosine in guinea-pig uterus. Acta physiol. scand. 105, 428436.

Verdugo, P., Blandau, R.J., Tam, P.Y. \& Halbert, S.A. (1976) Stochastic elements in the development of determined models of egg transport. In Ovum Transport and Fertility Regulation, pp. 126-137. Eds M. J. K. Harper, C. J. Pauerstein, C. E. Adams, E. M. Coutinho, H. B. Croxatto \& D. M. Paton. Scriptor, Copenhagen.

Verhage, H.G., Akbar, M. \& Jaffe, R.C. (1980) Cyclic changes in cytosol progesterone receptor of human Fallopian tube. J. clin. Endocr. Metab. 51, 776-780.

Youssefnejadian, E., Florensa, E., Collins, W. P. \& Sommerville, 1. F. (1972) Radioimmunoassay of plasmaprogesterone. J. Steroid Biochem. 3, 893901. 